\title{
Effectiveness of cartoon distraction on pain perception and distress in children during intravenous injection
}

\author{
Baljit Kaur ${ }^{1}$, Jyoti Sarin ${ }^{2}$, Yogesh Kumar ${ }^{3}$ \\ ${ }^{I}$ Ms. Baljit Kaur, Nursing Tutor,Maharishi Markandeshwar College of Nursing, Mullana, Ambala, Maharishi \\ Markandeshwar University,, Mullana, Ambala. \\ ${ }^{2}$ Dr. (Mrs.) Jyoti Sarin, RN.RM. MN. Ph.D. (Nursing), Director-Principal,Maharishi Markandeshwar, College \\ of Nursing, Mullana, Ambala, Maharishi Markandeshwar University,, Mullana, Ambala. \\ ${ }^{3}$ Mr. Yogesh Kumar, RN. RM. M.Sc. ( Nursing) Associate Professor, Dept. Child Health Nursing, Maharishi \\ Markandeshwar College of Nursing, Mullana, Ambala, Maharishi Markandeshwar University,, Mullana, \\ Ambala.
}

\begin{abstract}
Background: Intravenous injection is a medical procedure, often accompanied by pain and distress in children. Thus the reduction of such pain and distress becomes the responsibility of health care professionals to an extent as possible while maintaining patient safety by using various pharmacological and non pharmacological interventions.

Method: A quasi - experimental study was undertaken on children of 4 to 12 years age who were undergoing intravenous injections to determine the effectiveness of "Cartoon Distraction" as a strategy to reduce the pain perception and distress. The study comprised of 30 children selected through purposive sampling method. In present study the assessment of pain and distress done in morning without cartoon distraction and in evening with cartoon distraction at initiation, at five minutes and at termination of administration of intravenous injection on FACES pain scale and on distress assessment scale respectively on day 1 . While on day 2, to understand the diurnal effect of pain and distress, there was assessment of pain and distress in morning with cartoon distraction and in evening without cartoon distraction at initiation, at five minutes and at termination of administration of intravenous injection
\end{abstract}

Result: The results revealed that there is significantly $(p<0.005)$ less pain and distress in children with cartoon distraction at initiation, at five minutes and at termination of administration of intravenous injection. The findings also revealed that there is no influence of gender on perception of pain but there was an inverse relation of behavior pain response with age of the child. Children who had history of previous hospitalization had an increased perception of pain and distress during the current hospitalization. Pain and distress is also directly proportional to time duration of administration of intravenous injection and number of intravenous injection per day and the presence of caregiver had no role on the same.

Conclusion: It was concluded that cartoon distraction is an effective distraction strategy to reduce pain and distress among children during intravenous injection.

Keywords: Effectiveness, Cartoon Distraction, Pain perception, Distress and Intravenous Injection.

\section{Introduction:}

In a hospital setting, children often experience unpredictable and severe procedure-related pain that can be associated with negative emotional and psychological implications. ${ }^{1}$ Pain in children with acute and chronic diseases is a major public health problem that has been increasing over the last 20 years. ${ }^{2}$ In 1995 the American pain society challenged all health care system, to make pain the fifth vital sign along with pulse, temperature, blood pressure and respiration In addition to the pain associated with medical procedures, they are often a source of anxiety, fear, and behavioral distress for children and their families, which can further intensify their pain and interfere with the procedure. Medical procedures, particularly needles, are among the most feared experiences of children. ${ }^{4}$ Reports from children, parents and nurses consistently indicate that many children do indeed fear the "shot ${ }^{2}$." Estimates say that the percentage of pain is from $50-80 \%$ of all hospitalized children. The data summary for 1992 to 2004 from the American Pain Society reveals $70 \%$ of hospitalized children reported pain, almost $30 \%$ reported moderate pain and $15 \%$ reported extremely severe pain. ${ }^{5}$

Intravenous injection is one of the most commonly experienced procedures by children ${ }^{6}$ and $50 \%$ of children experience significant levels of pain and distress during intravenous injection. ${ }^{7}$ Intravenous injection differs from other needle procedures such as immunization, as it is longer, thereby making it more anxiety provoking for children.

Pain and distress can be managed by using both pharmacological and non-pharmacological method. To ensure adequate pain and distress relief and to give the children a sense of control over the situation, nonpharmacological methods are widely accepted as additional strategies that may be used independently or in 
addition to pharmacological methods. ${ }^{8}$ Distraction out of other non-pharmacological interventions is the most commonly used method for procedural pain and distress. ${ }^{9}$ Distraction is a non-pharmacological intervention that diverts attention from a noxious stimulus through passively redirecting the subject's attention or by actively involving the subject in the performance of diversion task ${ }^{10}$. Distraction method includes visual distraction (counting objects, watching TV), vocal distraction (listening to music), touch-motion distraction (slow regular breathing), and purposive distraction (using toys). Other interventions include relaxation, hypnosis, modeling, desensitization, contingency management, selective attention, stress inoculation, cognitive restructuring, and coping skills training. ${ }^{11}$

Of the distraction methods used during school age, audio-visual distraction is the most effective ${ }^{12}$. Audio-visual distraction like cartoon distraction is a simple, labor saving and easy to administer therapy that relieves pain and distress in children during intravenous injection procedures as equally and effectively as common psychological interventions ${ }^{13}$.

Carton distraction works on principle of ACCEPTS that is distract with activities i.e. watching cartoon video, distract with contributing i.e. cartoon video take the attention away from own pain and concentrate on concern for someone else, distract with comparisons - cartoon video help to compare own situation with one that is much worse, distract with opposite emotions- cartoon video helps to promote the complete opposite emotion i.e. help to laugh even if feeling very sad, distract by pushing away i.e. cartoon video helps in pushing the stressful situation away, distract by positive thought i.e. cartoon distraction direct concentration to other, more positive thoughts and distract with other sensations i.e. cartoon distraction has the ability to jog emotions and break the connection between person and his/her emotional pain. ${ }^{14}$

Cartoon distraction help nurses to solve the problem of lack of attention to pain relief, while saving nurses' time and make it possible for them to pay more attention to their jobs. ${ }^{15}$

The goal of the present treatment study was to develop a practical and cost effective means of reducing child pain and distress during intravenous injection. The intervention consisted of distraction in the form of popular children's cartoon movies Tom and Jerry Tales.

\section{Objectives}

1. To assess and compare pain perception in children with and without cartoon distraction during intravenous injection.

2. To assess and compare distress in children with and without cartoon distraction during intravenous injection.

3. To determine relationship between pain perception and distress in children with and without cartoon distraction during intravenous injection.

4. To determine association of level of pain perception in children with and without cartoon distraction during intravenous injection with selected variables.

5. To determine association of level of distress in children with and without cartoon distraction during intravenous injection with selected variables.

\section{Materials \& Methods}

A quasi experimental design was used in the study. The present study was conducted in different pediatric units of Doaba Hospital, Jalandhar, Punjab and M.M.I.M.S. \& R Hospital, Mullana, Ambala, Haryana. Doaba Hospital, Jalandhar Punjab which is 50 bedded children hospital with bed occupancy rate is about 50 . M.M.I.M.S. \& R Hospital, Mullana, Ambala, Haryana is 815 bedded multi-specialty hospital. There are total four paediatric units in the hospital, i.e 1 Pediatric ICU and 3 pediatric wards. After getting the approval of ethical committee, written permission was taken from from Principal of M.M.I.M.S. \& R. Hospital, Mullana, Ambala and Dr. Ashutosh Gupta of Doaba Hospital, Jalandhar was obtained. Final study was conducted during the month of December 2012 to January 2013. Thirty children undergoing intravenous injection were selected according to the inclusion and exclusion criteria using purposive sampling method. Children within the age group of 4-12 years, present at the time of data collection and receiving one same selected intravenous injection (Amikacin, Ceftriaxone, Amoxiclav and Meropenum) diluted in normal saline administered directly through fixed cannula twice a day for two consecutive days are included in study. Children undergoing any painful procedure, administration of analgesics, sedatives within hours of duration before Intravenous injection, receiving intravenous fluids, having thrombophelibitis at site of cannula, unconscious children and having facial palsy, peripheral nerve palsy, compartment syndrome, skin and soft tissue necrosis were excluded from the study. Written informed consent was taken from care giver of the child before including him/ her for the study. The tools used for the study included performa for personal and clinical variables i.e. name, age, gender, ward, CR. No., date of admission, diagnosis, address as personal variables and clinical variables as past history of illness, accident and injuries, previous hospitalization, previous duration of hospital stay, present duration of hospitalization, intravenous injection prescribed, time duration of administration of intravenous injection 
prescribed, duration of intravenous cannula insertion, site of cannulation, size of cannula, allergy to any drugs, number of intravenous injections per day and care giver present during the administration of intravenous injection

\section{Standardized FACES pain scale:}

Standardized FACES pain scale was used to depict pain perception in children. The scale shows a series of faces ranging from a happy face at 0 , "No hurt" to a crying face at 10 "Hurts worst" with maximum score as 10 and minimum as 0 categorized as 0 - No Hurts, 2 - Hurts Little Bit, 4 - Hurts Little More, 6 Hurts Even More, 8 - Hurts Whole Lot and 10 - Hurts Worst. The researcher chose the face that best described how child feels during intravenous injection.

\section{Distress Assessment Scale for Children.}

Distress Assessment Scale for Children was used to depict distress in children. This scale include three behavioral parameters - Physical, Emotional and physiological with maximum Score - 18 and Minimum Score - 0 categorized as 0 - no distress, 1-6 - mild distress, 7-12 - moderate distress and 13- 18 - severe distress.

Information regarding selected personal and clinical variables obtained through interviewing the care giver and reviewing the hospital record of the child and for assessing pain and distress on day 1 for the injection scheduled at 10:00 am no treatment was instituted and simultaneously to collect baseline pain and distress scores facial expression and behavioral responses of child during intravenous injection was videotaped with the purpose to code pain and distress at initiation, at five minutes and at termination of administration of intravenous injection on FACES pain scale and on distress assessment scale respectively by the researcher and for the injection scheduled at 10:00 pm treatment was instituted and likewise facial expression and behavioral responses of child were video recorded to code pain and distress at initiation, at five minutes and at termination of administration of intravenous injection. While on day two, to understand the diurnal effect of pain and distress, for the injection scheduled at 10:00 am treatment was instituted and for the injection scheduled at 10:00 pm no treatment was instituted and likewise facial expression and behavioral responses of child were video recorded to code pain and distress at initiation, at five minutes and at termination of administration of intravenous injection.

The data was analyzed according to the objectives of the study using both descriptive and inferential statistics. Calculation was carried out with the help of Microsoft Excel and Statistical Package for Social Science (SPSS version 17) Program. The various statistical measures used were the frequency distribution, mean, mean difference, standard error of mean difference standard deviation, $t$ test and chi square to find the statistical significance.

Description of sample characteristics

III. Results

Frequency and percentage were computed for describing sample characteristics. The findings are presented in table 1.

Table 1: Frequency and Percentage Distribution of Characteristics of Children

\begin{tabular}{|c|c|c|c|}
\hline S. No. & Selected Variables & f & $\%$ \\
\hline 1. & Gender & & \\
\hline 1.1 & Male & 17 & 56.67 \\
\hline 1.2 & Female & 13 & 43.33 \\
\hline 2. & Age of Child & & \\
\hline 2.1 & $4-\leq 7$ years & 23 & 76.67 \\
\hline 2.2 & $>7-12$ years & 07 & 43.33 \\
\hline 3. & Past history of illness & & \\
\hline 3.1 & Medical illness & $\mathbf{1 0}$ & 66.67 \\
\hline 3.2 & Surgical illness & 05 & 33.33 \\
\hline 4. & Accident and injuries & & \\
\hline 4.1 & Present & 05 & 16.67 \\
\hline 4.2 & Not Present & 25 & 83.33 \\
\hline 5. & Previous Hospitalization & & \\
\hline 5.1 & Present & 13 & 43.33 \\
\hline 5.2 & Not Present & 17 & 56.67 \\
\hline 6. & $\begin{array}{l}\text { Previous duration of hospital } \\
\text { stay }\end{array}$ & & \\
\hline 6.1 & $\leq 5$ days & 07 & 53.85 \\
\hline 6.2 & $>5$ days & 06 & 46.15 \\
\hline 7. & $\begin{array}{l}\text { Present duration of } \\
\text { hospitalization }\end{array}$ & & \\
\hline 7.1 & $\leq 48$ hours & 23 & 76.67 \\
\hline
\end{tabular}




\begin{tabular}{|c|c|c|c|}
\hline 7.2 & $>48$ hours & 07 & 23.33 \\
\hline 8. & Intravenous injection prescribed & & \\
\hline 8.1 & Amikacin & 09 & 30.00 \\
\hline 8.2 & Ceftriaxone & 14 & 46.70 \\
\hline 8.3 & Amoxiclav & 03 & 10.00 \\
\hline 8.4 & Meropenum & 04 & 13.30 \\
\hline 9. & $\begin{array}{l}\text { Time duration of administration } \\
\text { of Intravenous injection } \\
\text { prescribed }\end{array}$ & & \\
\hline 9.1 & $\leq 10$ minutes & 16 & 53.33 \\
\hline 9.2 & $>10$ minutes & 14 & 46.67 \\
\hline $\begin{array}{l}10 . \\
0\end{array}$ & $\begin{array}{l}\text { Duration of intravenous cannula } \\
\text { insertion }\end{array}$ & & \\
\hline 10.1 & $\leq 48$ hours & 23 & 76.67 \\
\hline 10.2 & $>48$ hours & 07 & 23.33 \\
\hline $\begin{array}{l}11 . \\
1\end{array}$ & Site of cannulation & & \\
\hline 11.1 & Cephalic vein & 10 & 33.33 \\
\hline 11.2 & Metacarpal vein & 14 & 46.67 \\
\hline 11.3 & Median vein & 06 & 20.00 \\
\hline $\begin{array}{l}12 . \\
2\end{array}$ & Size of cannula & & \\
\hline 12.1 & 22 gauze & 07 & 23.33 \\
\hline 12.2 & 24 gauze & 23 & 76.67 \\
\hline $\begin{array}{l}13 . \\
3\end{array}$ & Allergy to any drugs & & \\
\hline 13.1 & Present & 07 & 23.33 \\
\hline 13.2 & Not Present & 23 & 76.67 \\
\hline $\begin{array}{l}14 . \\
4 .\end{array}$ & $\begin{array}{l}\text { Number of } \\
\text { injections per day }\end{array}$ & & \\
\hline 14.1 & $\leq 6$ & 19 & 63.33 \\
\hline 14.2 & $>6$ & 11 & 36.67 \\
\hline $\begin{array}{l}15 . \\
5\end{array}$ & $\begin{array}{l}\text { Care giver present during the } \\
\text { Intravenous injection }\end{array}$ & & \\
\hline 15.1 & Father & 03 & 10.00 \\
\hline 15.2 & Mother & 13 & 43.33 \\
\hline 15.3 & Father and Mother both & 12 & 40.00 \\
\hline 15.4 & Grandparents & 02 & 06.67 \\
\hline
\end{tabular}

\section{Assessment and comparison of the pain perception in children with and without cartoon distraction during intravenous injection.}

At initiation of administration of intravenous injection with cartoon distraction $40 \%$ of children on day 1 and $43.33 \%$ on day 2 had level of pain as hurts little more whereas without cartoon distraction $66.70 \%$ on day 1 and $56.70 \%$ on day 2 as hurts worst.

Similarly at five minutes of administration of intravenous injection with cartoon distraction $46.70 \%$ of children on day 1 had level of pain as hurts little more and $63.33 \%$ on day 2 as hurts little bit whereas without cartoon distraction $56.70 \%$ on day 1 as hurts worst and $60 \%$ on day 2 as hurts whole lot.

Likewise at termination of administration of intravenous injection with cartoon distraction $43.33 \%$ of children on day 1 had level of pain as hurts little bit and $63.33 \%$ on day 2 as no hurts whereas without cartoon distraction in $53.33 \%$ of children on day 1 and $56.70 \%$ on day 2 as hurts whole lot.

Comparison of the pain perception in children with and without cartoon distraction on Day 1 and 2 shown in table 2 revealed that the mean pain score of children without cartoon distraction at initiation (9.20, $8.93)$, at five minute $(9.07,3.30)$ The table 2 revealed that the mean pain score of children without cartoon distraction at initiation $(9.20,8.93)$, at five minute $(6.00,6.40)$ and at termination $(7.76,0.73)$ of intravenous injection were higher than the mean pain score of children with cartoon distraction at initiation (4.20, 3.60), at five minute $(3.07,1.03)$ and at termination $(1.53,0.17)$ of intravenous injection on day 1 and day 2 respectively. It further showed that ' $\mathrm{t}$ ' value calculated between mean pain score of children with and without cartoon distraction at initiation (' $t$ ' $(29)=11.45,13.76)$, at five minute (' $t$ ' $(29)=16.15,20.69)$ as well as at termination ( $\mathrm{t}$ ' $(29)=15.10,18.95)$ of administration of intravenous injection were found to be statistically significant at 0.05 level of significance 
Table 2:Mean, Mean Difference, Standard Error of Mean Difference and " $t$ " value of Pain Score of Children With and Without Cartoon Distraction At Initiation, At Five Minute and At Termination of Administration of Intravenous Injection at Day 1 and Day 2

\begin{tabular}{|c|c|c|c|c|c|c|c|}
\hline \multirow[t]{3}{*}{ Days } & \multirow{3}{*}{$\begin{array}{l}\text { Time of administration } \\
\text { of intravenous injection }\end{array}$} & \multicolumn{2}{|c|}{ Children } & \multirow[b]{3}{*}{$\mathbf{M}_{\mathbf{D}}$} & \multirow[b]{3}{*}{$\mathbf{S D}_{\mathrm{D}}$} & \multirow[b]{3}{*}{$\mathbf{S E}_{\mathrm{MD}}$} & \multirow[b]{3}{*}{ ' $t$ ' } \\
\hline & & $\begin{array}{c}\text { With } \\
\text { Cartoon } \\
\text { distraction } \\
\text { (Evening) }\end{array}$ & $\begin{array}{l}\text { Without } \\
\text { Cartoon } \\
\text { distraction } \\
\text { (Morning) }\end{array}$ & & & & \\
\hline & & Mean & Mean & & & & \\
\hline \multirow{5}{*}{ Day 1} & At initiation & 4.20 & 9.20 & 5.00 & 2.39 & 0.35 & $11.45^{*}$ \\
\hline & At 5 min. & 3.07 & 9.07 & 6.00 & 2.03 & 0.28 & $16.15^{*}$ \\
\hline & At termination & 1.53 & 7.67 & 6.13 & 2.22 & 0.34 & $15.10^{*}$ \\
\hline & & $\begin{array}{c}\text { With Cartoon } \\
\text { distraction } \\
\text { (Morning) } \\
\end{array}$ & $\begin{array}{c}\text { Without Cartoon } \\
\text { distraction } \\
\text { (Evening) }\end{array}$ & & & & \\
\hline & At initiation & 3.60 & 8.93 & 5.33 & 2.12 & 0.36 & $13.76^{*}$ \\
\hline \multicolumn{8}{|l|}{ Day 2} \\
\hline & At 5 min. & 2.13 & 8.53 & 6.40 & 1.69 & 0.29 & $20.69 *$ \\
\hline & At termination & 0.87 & 7.27 & 6.40 & 1.85 & 0.29 & $18.95^{*}$ \\
\hline
\end{tabular}

Determination of impact of day time i.e., Morning $10 \mathrm{am}$ and evening $10 \mathrm{pm}$ on pain perception in children during intravenous injection

It was established that with cartoon distraction the mean pain score at evening was higher than mean pain score at morning. As due to tiredness, lethargy and fatigue in evening children paid less attention towards cartoon distraction and thus pain perception in children increased in evening with cartoon distraction which shows the diurnal variations in the level of pain among children during intravenous injection. Moreover on day 1 cartoon distraction was a newer intervention and on day 2 child was better acquainted to intervention perceived less pain with cartoon distraction. Without cartoon distraction though the mean pain score at morning was higher than mean pain score at evening as due to in morning child more active directed more attention towards the intravenous injection thus perceive more pain but not significant difference between pain scores in morning and evening indicated no diurnal variation in level of pain among children.

Assessment and comparison of distress in children with and without cartoon distraction during intravenous injection.

At initiation of administration of intravenous injection with cartoon distraction $53.33 \%$ of children on day 1 had mild distress and $55.33 \%$ on day 2 had moderate distress whereas without cartoon distraction $86.70 \%$ on day 1 and $80 \%$ on day 2 had severe distress.

Similarly at five minutes of administration of intravenous injection with cartoon distraction $63.33 \%$ of children on day 1 and $70 \%$ on day 2 had mild distress whereas without cartoon distraction $76.70 \%$ on day 1 and day 2 had severe distress

Likewise at termination of administration of intravenous injection with distraction $93.33 \%$ of children on day 1 and $90 \%$ on day 2 had mild distress whereas without cartoon distraction $53.33 \%$ on day 1 had moderate distress and $63.33 \%$ had severe distress.

Comparison of distress in children with and without cartoon distraction on Day 1 and 2 shown in table 3 
Table 3: Mean, Mean Difference, Standard Error of Mean Difference and " $t$ " value of Distress Score of Children With and Without Cartoon Distraction At Initiation, At Five Minute and At Termination of Administration of Intravenous Injection at Day 1 and Day 2

\begin{tabular}{|c|c|c|c|c|c|c|c|}
\hline \multirow[t]{2}{*}{ Days } & \multirow{2}{*}{$\begin{array}{l}\text { Time of administration } \\
\text { of intravenous injection }\end{array}$} & \multicolumn{2}{|c|}{ Children } & \multirow[b]{2}{*}{$\mathbf{M}_{\mathbf{D}}$} & \multirow[b]{2}{*}{$\mathbf{S D}_{\mathbf{D}}$} & \multirow[b]{2}{*}{$\mathrm{SE}_{\mathrm{MD}}$} & \multirow[b]{2}{*}{ ' $t$ ' } \\
\hline & & $\begin{array}{c}\text { With } \\
\text { Cartoon } \\
\text { distraction } \\
\text { (Evening) } \\
\text { Mean }\end{array}$ & $\begin{array}{c}\text { Without } \\
\text { Cartoon } \\
\text { distraction } \\
\text { (Morning) } \\
\text { Mean }\end{array}$ & & & & \\
\hline \multirow{4}{*}{ Day 1} & At initiation & 6.80 & 15.00 & 8.20 & 3.88 & 0.65 & $11.57 *$ \\
\hline & At 5 min. & 5.77 & 14.13 & 8.37 & 3.63 & 0.58 & $12.61 *$ \\
\hline & At termination & 3.87 & 12.37 & 8.50 & 3.43 & 0.60 & $13.57 *$ \\
\hline & & $\begin{array}{c}\text { With Cartoon } \\
\text { distraction } \\
\text { (Morning) } \\
\end{array}$ & $\begin{array}{c}\text { Without Cartoon } \\
\text { distraction } \\
\text { (Evening) }\end{array}$ & & & & \\
\hline \multirow{4}{*}{ Day 2} & At initiation & 6.65 & 14.87 & 8.33 & 2.56 & 0.44 & $17.80 *$ \\
\hline & & & & & & & \\
\hline & At 5 min. & 5.50 & 13.73 & 8.23 & 2.31 & 0.38 & $19.48 *$ \\
\hline & At termination & 4.50 & 12.17 & 7.67 & 2.91 & 0.56 & $14.39 *$ \\
\hline
\end{tabular}

The table 3 revealed that the mean distress score of children without cartoon distraction at initiation $(15.00,14.87)$, at five minute $(14.13,13.73)$ and at termination $(12.37,12.17)$ of intravenous injection were higher than the mean distress score of children with cartoon distraction at initiation $(6.80,6.65)$, at five minute $(5.77,5.50)$ and at termination $(3.87,4.50)$ of intravenous injection on day 1 and day 2 respectively. It further showed that ' $\mathrm{t}$ ' value calculated between mean distress score of children with and without cartoon distraction at initiation (' $t$ ' $(29)=11.57,17.80)$, at five minute (' $t$ ' $(29)=12.61,19.48)$ as well as at termination (' $t$ ' $(29)=13.57$, 14.39) of administration of intravenous injection were found to be statistically significant at 0.05 level of significance.

\section{Determination of impact of day time i.e., Morning 10am and evening 10pm on distress in children during intravenous injection}

There was no significant difference in mean distress score at morning and evening on Day 1 and 2 with and without cartoon distraction which shown no diurnal variations in the level of distress among children during intravenous injection.

\section{Correlation of pain perception with distress with and without cartoon distraction.}

At initiation, at five minutes and at termination of administration of intravenous injection with cartoon distraction, there was moderate positive correlation $(0.66,0.42,0.27)$ between pain perception and distress in children which is significant at 0.05 level of significance.

Similarly at initiation, at five minutes and at termination of administration of administration of intravenous injection without cartoon distraction, there was high positive correlation $(0.93,0.78,0.82)$ between pain perception and distress in children which is significant at 0.05 level of significance.

\section{Factors influencing the outcome of the procedure}

The findings also revealed that there is no influence of gender on perception of pain but there was an inverse relation of behavior pain response with age of the child. Children who had history of previous hospitalization had an increased perception of pain and distress during the current hospitalization. Pain and distress is also directly proportional to time duration of administration of intravenous injection and number of intravenous injection per day and the presence of caregiver had no role on the same.

\section{Discussion}

The purpose of the present study was to assess and evaluate the effect of cartoon distraction on pain perception and distress during intravenous injection. Our study showed that watching cartoon video influenced children's pain perception and distress at initiation, at five minutes and at termination of administration of 
intravenous injection. Findings of this study revealed that cartoon distraction had significant effect on pain perception and distress.

Analysis of this study indicates the significant reduction in pain and distress in children with cartoon distraction during intravenous injection. Bellieni CV et al.surveyed 69 children aged 7-12 years undergoing Intravenous injection with the use of the Oucher scale, and found that TV watching (ie watching an age appropriate cartoon on TV) was more effective than active distraction performed by their mothers. ${ }^{16}$

The result of present study showed that cartoon distraction therapy is effective in reducing pain in children during painful medical procedure. Which are consistent with previous investigationsby Rockville, MD (1992) that distraction and adult coaching appear to be beneficial for young children undergoing painful medical procedures. ${ }^{3}$ Finding of present study also consistent the findings of the study conducted by Zi-XuanWanga, Li-Hui Sun (2008) that though the difference between the audiovisual distraction and control groups did not reach statistical significance $(\mathrm{P}=0.064)$, a change in degree of cooperation from $81 \%$ (Grade 0 and 1 patients in the control group) to $92 \%$ ( audiovisual distraction group) would be considered by most to be of clinical significance which indicated that watching cartoon films can decrease pain and improve the cooperative attitude of children as effectively as routine psychological intervention and seems to be beneficial to the further process. ${ }^{17}$

The result of present study showed that cartoon distraction therapy is effective in reducing pain in children at initiation, at five minute and at termination of administration of intravenous injection. Findings are consistent with study conducted by Gonzalez, J. C , Routh, D. K., \& Armstrong, F. D. (1993) on Effects of audio visual distraction versus reassurance on children's reactions to injections which showed that audio visual distractions are effective in decreasing pain as mean pain score $<5 \mathrm{~min}=2.9,15 \mathrm{~min}=1.82$ and $30 \mathrm{~min}=$ $0.3{ }^{18}$ Another study by Pringle et.al. (2003) examined the effectiveness of an intervention for reducing behavioral distress in children during needle sticks. The distress management intervention included instruction for children to engage in a distraction activity during needle sticks and parent training in coaching their children. Results indicated that he child distress was significantly and negatively related to use of the experimental distracter. $^{19}$

Present study depicts positive significant correlation between pain perception and distress measures on FACE pain scale and Distress assessment scale. Findings are consistent with previous study Cohen LL, Blount RL, Cohen RJ, Schaen ER, Zaff JF showed positive significant relationship between FLACC pain scale and CAMPIS-R distress assessment scale used in depicting child pain perception, child coping and distress during BMA/LP procedures. ${ }^{2}$

Craig K.D. (2002) states that the intensity of pain behavior during invasive proceduresdecreases with the age of the child i.e., younger children responds to painfulprocedures with more distress than older children. ${ }^{20}$ The present study also suggested the same i.e. as the age increases the perception of pain and distress decreases. Several researchers have reported that children's exposure to past painful procedures is inversely related to their behavioral responses to a venipuncture. A cycle of increased anxiety, fear, and pain can result from negative experiences with injections, which in turn can exacerbate future injection experiences. ${ }^{21}$

Children with a history of negative medical experiences showed higher levels of anxiety before a venipuncture procedure, and were more distressed and less cooperative during the procedure. ${ }^{22,23}$ The present study also showed that those children who had previous hospitalization more than five days depicted increased sign of perception of pain at initiation, at five minute and at termination of administration of intravenous injection. However, in another study, this relationship did not reach statistical significance. ${ }^{24}$

\section{Implications}

The findings of the present study have implications for child health nursing practice, nursing administration, nursing education and nursing research.

\section{Nursing Practice}

The nurses working in clinical area as well as community settings should follow the practice of cartoon distraction during Intravenous injection in order to reduce pain and distress related to Intravenous injection.

Pain and distress assessment and its management through distraction technique should be made mandatory in all pediatric units.

\section{Nursing Education}

To equip nurses to provide holistic care, nursing curriculum need to cover non pharmacological measures such as distraction technique i.e., play therapy for pain and distress management in children and reinforced in their clinical practice.

\section{Nursing Administration}

Nurse administrator should develop nursing practice standards, protocols and manuals for pain and distress assessment and its management in children of various age group which should include distraction 
technique example cartoon distraction therapy as an important strategy to relieve pain and reduce level of distress in children.

Nurse administrators have the responsibility to provide a staff development programme for the nursing personnel emphasizing use of distraction technique i.e., cartoon distraction to reduce pain and level of distress during painful pediatric procedures especially during Intravenous injection administration.

Nurse administrator should ensure the availability of variety of age appropriate distraction techniques in sufficient number in the pediatric units kept in separate play rooms and supervise the usage.

\section{References}

[1]. Cummings EA, Reid GJ, Finley GA, McGrath PJ, Ritchie JA. Prevalence and source of pain in pediatric inpatients. Journal of Pain 1996; 68: 25-31.

[2]. Cohen LL. Behavioral approaches to anxiety and pain management for pediatric venous access. Journal of Pediatrics 2008;122:1349.

[3]. Rockville, MD. Acute pain management in infants, children and adolescents- Operative and medical procedures. Agency for Healthcare Policy and Research (AHCPR) Publications; 1992.

[4]. Broome ME, Bates TA, Lillis PP, McGahee TW. Children's medical fears, coping behaviors, and pain perceptions during a lumbar puncture. Oncology Nursing Forum 1990; 17: 361-7.

[5]. Taddio A. Effects of early pain experience (the human literature). In: McGrathPJ, Finley A, eds. Chronic and recurrent pain in children and adolescents: progress inpain research and management. Vol. 13. Seattle: IASP Press; 1999. p. 57-74.

[6]. Gupta D, Agarwal A, Dhiraaj S, Tandon M, Kumar M.Singh PK, et al. An evaluation of efficacy of balloon inflation on venous cannulation pain in children: A prospective, randomized, controlled study. Anesthesia and Analgesia 2006; 102: 1372-5.

[7]. Fradet C, McGrath PJ, Kay J, AdamsS, Luke B. A prospective survey of reactions to blood tests by children and adolescents. Pain 1990; 40(1):53-60.

[8]. Uman LS, Chambers CT, McGrath PJ, et al. Psychological interventions for needle-related procedural pain and distress in children and adolescents. Cochrane Database Systemic Review 2006;(4):CD005179.

[9]. Eland. Jann M. Pain in Children. Nursing Clinics of North America 1990;33(4):33

[10]. Vessey, J., Carlson, K., \& McGill, J. (1994). Use of distraction with children during an acute pain experience. Journal of Nursing Research; 43: 369-371.

[11]. Cohen LL, MacLaren JE, Fortson BL, Friedman A, DeMore M, Lim CS, et al. Randomized clinical trial of distraction for infant immunization pain. Journal of Pain. 2006;125(1-2):165-171.

[12]. Uman LS, Chambers CT, McGrath PJ, et al. Psychological interventions for needle-related procedural pain and distress in children and adolescents. Cochrane Database Systemic Review 2006;(4):CD005179.

[13]. Devine, K., Benoit, M., Simons, L. E., Cheng, P. S., Seri, L. G., \& Blount, R. L. Psychological interventions for Windich-Biermeier et al. Journal of Pediatric Oncology Nursin2007; 24(1) The Suffering Child, 6, 1-22. Retrieved June 19, 2004

[14]. Cohen LL, Blount RL, Cohen RJ, Schaen ER, Zaff JF. Comparative study of distraction versus topical anesthesia for pediatric pain management during immunizations. Journal of Health Psychology 1999;18(6):591-8.

[15]. DeMore M, Cohen L. Distraction for Pediatric Immunization Pain: A Critical Review. Journal of Clinical Psychology in Medical Settings. 2005;12(4):281-91.

[16]. Bellieni CV, Cordelli DM, Raffaelli M, Ricci B, Morgese G, Buonocore G. Analgesic effect of watching TV during venepuncture. Journal of Child Psychology 2006;91(12):1015-7.

[17]. Zi-XuanWanga Li-HuiSunb and Ai-Ping Chena. The efficacy of non-pharmacological methods of pain management in school age children receiving venepuncture in a paediatric department: a randomized controlled trial of audiovisual distraction and routine psychological intervention.Swiss Med Wkly 2008;138(39-40):579-584

[18]. Gonzalez, J. C , Routh, D. K., \& Armstrong, F. D. (1993) on Effects of audio visual distraction versus reassurance on children's reactions to injections. Journal of Pediatric Nursing 2010;7(1):133-39.

[19]. Pringle B, Hilley L, Gelfand K, Dahlquist LM, Switkin M, Diver T etal. Decreasing Child Distress During Needle Sticks and Maintaining Treatment Gains Over Time. Journal of clinical psychology in medical settings 2003; 8 (2): 119-30

[20]. Craig KD. Pain in infants and children: Socio developmental variations on the theme. An Updated Review. Refresher Course Syllabus. World Congress on Pain, San Diego, CA. Seattle.10th ed. IASP Press, 2002;305-14

[21]. Fowler-Kerry S, Lander JR. Management of injection pain in children. Journal of Pain 1987 Aug; 30(2):169-75.

[22]. Fitzgerald M, Beggs S. The neurobiology of pain: Developmental aspects. Neuroscientist 2001; 7:246-57.

[23]. Bijttebier P, Vertommen H. The Impact of previous experience onchildren's reactions to venepuncture. Journal of Health Psychology 1998; 3:39-46.

[24]. Manne SL, Redd WH, Jacobsen PB, Gorfinkle K, Schorr O, Rapkin B. Behavioral intervention to reduce child and parent distress during venipuncture. Journal of Consultant Clinical pychology 1990; 58: 565-72. 